\title{
Microbial Diversity in Time and Space
}




\title{
Microbial Diversity in Time and Space
}

\author{
Edited by \\ R. R. Colwell \\ University of Maryland \\ College Park, Maryland \\ Usio Simidu \\ Tokyo University of Agriculture \\ Tokyo, Japan \\ and \\ Kouichi Ohwada \\ University of Tokyo \\ Tokyo, Japan
}

Plenum Press • New York and London 


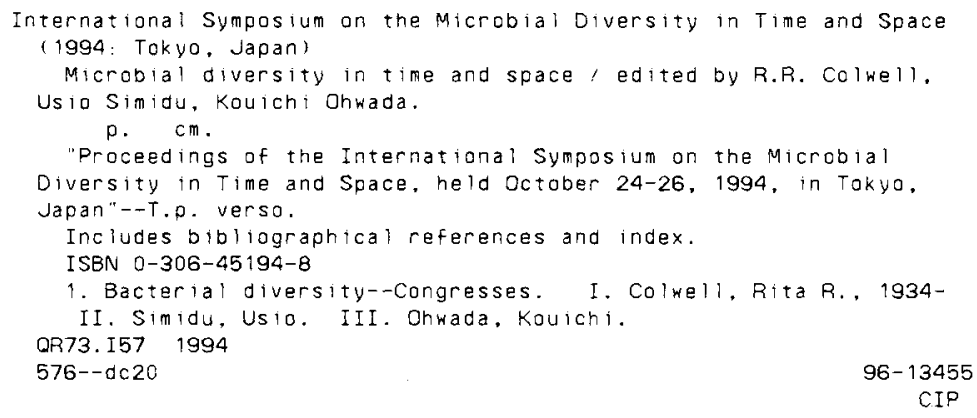

Proceedings of the International Symposium on the Microbial Diversity in Time and Space, held October 2426,1994 , in Tokyo, Japan

ISBN 0-306-45194-8

(C) 1996 Plenum Press, New York

A Division of Plenum Publishing Corporation

233 Spring Street, New York, N. Y. 10013

\section{All rights reserved}

10987654321

No part of this book may be reproduced, stored in a retrieval system, or transmitted in any form or by any means, electronic, mechanical, photocopying, microfilming, recording, or otherwise, without written permission from the Publisher

Printed in the United States of America 


\section{PREFACE}

The symposium, "Microbial Diversity in Time and Space," was held in the Sanjo Conference Hall, University of Tokyo, Tokyo, Japan, October 24-26, 1994. The symposium was organized under the auspices of the Japanese Society of Microbial Ecology and co-sponsored by the International Union of Biological Sciences (IUBS), International Union of Microbiological Societies (IUMS), International Committee on Microbial Ecology (ICOME), and the Japanese Society of Ecology.

The aim of the symposium was to stress the importance of the global role of microorganisms in developing and maintaining biodiversity. Twenty-four speakers from seven countries presented papers in the symposium and in the workshop, "Microbial Diversity and Cycling of Bioelements," that followed the symposium. Papers presented at the symposium are published in this proceedings. Discussions of the workshop, which were energetic and enthusiastic, are also summarized in this proceedings.

The symposium provided an opportunity to address the role of microorganisms in global cycles and as the basic support of biodiversity on the planet. Previously unrecognized as both contributing to and sustaining biodiversity, microorganisms are now considered to be primary elements of, and a driving force in, biodiversity.

Financial support was provided for the symposium by the CIBA GEIGY Foundation for the Promotion of Science, Naito Foundation, and the Uchida Foundation of the Ocean Research Institute, University of Tokyo. Support from these foundations is gratefully acknowledged. 


\section{CONTENTS}

1. Microbial Biodiversity-Global Aspects $\ldots \ldots \ldots \ldots \ldots \ldots \ldots \ldots \ldots \ldots \ldots$ Rita R. Colwell

2. Importance of Community Relationships in Biodiversity $\ldots \ldots \ldots \ldots \ldots \ldots$ Hiroya Kawanabe

3. From Strains to Domains: Measuring the Degree of Phylogenetic Diversity among Prokaryotic Species and as Yet Uncultured Strains ........... 19 Erko Stackebrandt

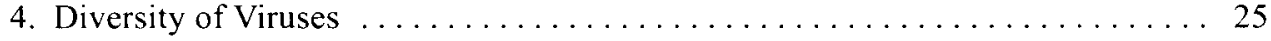
Masakazu Hatanaka

5. The Evolution of Fungal Diversity: Past, Present, and Future $\ldots \ldots \ldots \ldots \ldots 33$ Amy Y. Rossman

6. Fungal Diversity and Phylogeny with Emphasis on 18 S Ribosomal DNA

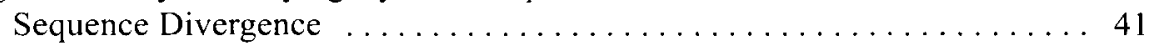
Junta Sugiyama, Takahiko Nagahama, and Hiromi Nishida

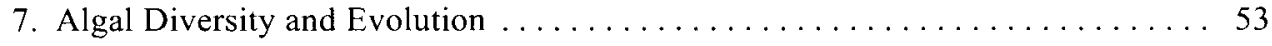
Hiroshi Oyaizu and Shigeto Ohtsuka

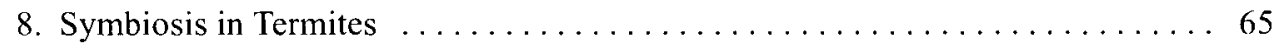
Ikuo Yamaoka

9. The Role of Microorganisms in Tri-Trophic Interactions in Systems Consisting of Plants, Herbivores, and Carnivores .................. 71 Marcel Dicke

10. Sensitivity Analysis in Microbial Communities .................. 85 H. Nakajima and Z. Kawabata

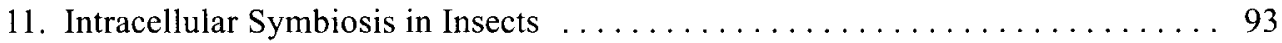
Hajime Ishikawa

12. Evolutionary Relationships of Catabolic Functions in Soil Bacteria ........ 101 Kensuke Furukawa, Nobutada Kimura, and Jun Hirose 
13. Adaptation of Soybean Bradyrhizobia to the Brazilian Edaphic Savannahs .... 109 M. Cristina P. Neves, Heitor L. C. Coutinho, and Norma G. Rumjanek

14. Viruses and DNA in Marine Environments ..................... 115 John H. Paul, Christina A. Kellogg, and Sunny C. Jiang

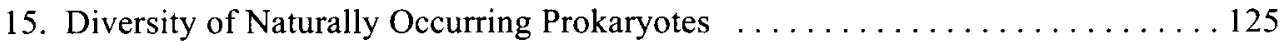
E. F. DeLong

16. The Internet and Microbial Ecology 135 Masao Nasu

17. Image Analysis of Bacterial Cell Size and Diversity 141 Kenji Kato

18. Microbial Diversity and the Cycling of Nitrogen in Soil Ecosystems ........ 149 Tohru Ueda and Kazuyuki Inubushi

19. The Role of Microbial Diversity in the Cycling of Elements. (Summary of

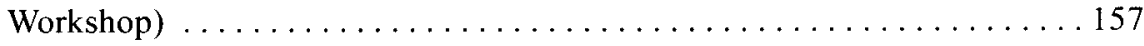
Rita R. Colwell

20. Summary of Workshop-Part 2: Microbial Species $\ldots \ldots \ldots \ldots \ldots \ldots \ldots \ldots \ldots$ Erko Stackebrandt 